of the foundation of this Society, microscopes were primitive and were generally regarded as playthings compared to the telescope, although Lister had already published his epoch-making paper on the achromatic objective. The paucity of microscopical research in Great Britain had, in fact, already been noted by Schleiden, a slur which the Society was to do much to remove. Under Prof. Owen as first president the Society flourished from the start, and the first number of the Journal was published in 1841. One of whe main features of the early meetings, attended in the nature of things almost exclusively by amateurs, was apparently the rapid introduction of new types of microscopes and much enthusiasm over technical improvements upon old. Among the members of the time we may note such names as John Queckett, Michael Faraday, Thomas Bell, with Ehrenberg as the first honorary fellow. Throughout its life the Society has stimula. ted interest not only in improvement of instruments but also in perfection of microscopical technique. The use of Canada balsam had been described shortly before the foundation of the Society, but it was not until 1848 that the use of glycerine was noted by Warrington.

In its first fifty years the Society achieved muchthe homogeneous immersion lens suggested by Stephenson and worked out by Abbe, the binocular microscope, the Society's standard screw for objectives, the mechanical substage and hundreds of other improvements large and small-and in its Journal were presented many epoch-making papers the authors of which are now almost forgotten but whose work has formed a sure foundation for modern studies. In more recent times the Society has become progressively professional. Among the outstanding features of these later years we may recall the controversy over Abbe's diffraction theory of microscopic vision, with E. M. Nelson and J. W. Gordon us the more notable figures and calling to mind such great names as Sylvanus Thompson and Lord Rayleigh, a topic which has arisen from time to time during ensuing years, culminating in 1928, when it was generally agreed that under the conditions of illumination commonly employed the theory is no longer tenable. In 1902 siedentopf introduced the ultra-microscope and in the following year the first paper appeared on ultra-violet light microscopy, marking perhaps the most important advance during the present century. The basis for the modern standard of procedure in microscopy was laid by Nelson in 1910 in a description of his method of "critical microscopy". Since that time, perhaps one of the more notable advances with which the Society has been connected is the improvement in design and the use of the polarizing microscope figuring so largely in current microscopy. It is confidently to be expected that in the future the Society will continue to serve microscopy with the same success as in the past. (See also Nature, 144, 850; 1939.)

\section{The Australian Anthropological Association}

In 1939 the Australian Anthropological Association was formed after discussion between the Anthropological Associations of New South Wales, Victoria and South Australia at the meeting of the Australian and New Zealand Association for the Advancement of Science held in Canberra that year. The headquarters of the new Association are to be situated in rotation for a period of two years in each State of the
Commonwealth in which there is an anthropological society affiliated with the Association. During the first two years of its existence the headquarters of the Association were in Adelaide. Now they are at Sydney and will remain there until October 1, 1943, when they will be transferred to Melbourne. The official organ of the Association is Mankind which is the official journal of the Anthropological Society of South Australia. Officers of the Association are as follows : President, Prof. A. P. Elkin ; Vice-president, Mr. F. L. S. Bell; Hon. Secretary-Treasurer, Mr. G. W. Watkins ("Hansard" Staff, Parliamentary House, Sydney).

\section{Early Civil Engineering in France}

IN a paper read to the Newcomen Society on March 11 entitled "The French Civil Engineers of the Eighteenth Century", Mr. S. B. Hamilton gave an account of the Corps des Ponts et Chaussées, founded in 1716, and of the school established in 1747 in connexion with it. The Corps was responsible for the main roads, canals, bridges, etc., of the country, and it has had many distinguished men on its staff. These men, such as Gautier, Frézier, Perronet, Gauthey, Chezy and Prony, possessed high scientific attainments, and in their memoirs and text books they established many of the principles underlying constructional work. When Telford looked for the literature of eivil engineering, it was to France he turned, and his collection of books was bequeathed to the Institution of Civil Engineers. The outstanding man of the eighteenth century was Perronet (1708-94), who entered the Corps in 1745 and became director of the École des Ponts et Chaussées in 1747. His bridges, said Mr. Hamilton, were remarkable for boldness of design. Moreover, in an age of corruption, he set his face against the patronage which ruined some civil administrations; he selected his subordinates strictly on the grounds of ability and character.

\section{Indian Journal of Genetics and Plant Breeding}

THE formation of the Indian Society of Genetics and Plant Breeding at New Delhi in January 1942 has been quickly followed by the publication of the Indian Journal of Genetics and Plant Breeding. This journal is edited by Dr. B. P. Pal, Imperial Agricultural Research Institute, New Delhi, on behalf of the executive council of the Society. This welcome addition to genetical publications provides a valuable outlet and source of reference for the everincreasing work of the research institutes of India. The volume for 1941 consists of one part, but in the succeeding years it is intended to publish twice a year.

In the first volume there are articles on hybrid vigour in rice by $K$. Ramiah and $K$. Ramasamy, chlorophyll deficiencies in rice by B. S. Kadam, colchicine induction of polyploids in Capsicum annuum by B. P. Pal, S. Ramanujam and A. S. Joshi, cytology of sterile Sesamum orientale by L. S. S. Kumar and A. Abraham and vernalization of Indian crop plants by B. P. Pal and G. Suryanarayana Murty. The Agricultural Commissioner with the Government of India, Dr. W. Burns, in the first paper of the publication, points out the great opportunities for plant geneties and plant breeding in India and welcomes the advent of the Society and Journal. 